\title{
Writing Philosophy as Poetry: Wittgenstein's Literary Syntax
}

\author{
Marjorie Perloff, Stanford
}

"His disposition," Bertrand Russell wrote of the young Wittgenstein in 1912, "is that of an artist, intuitive and moody." A similar judgment was made some fifteen years later by Rudolf Carnap in Vienna:

His point of view and his attitude toward people and problems ... were much more similar to those of a creative artist than to those of a religious prophet or a seer. When he started to formulate his view on some specific philosophical problem, we often felt the internal struggle that occurred in him at that very moment, a struggle by which he tried to penetrate from darkness to light under an intense and painful strain. ... When finally, sometimes after a prolonged and arduous effort, his answer came forth, his statement stood before us like a newly created piece of art or a divine revelation. (Monk 1990, 244).

And Wittgenstein himself, hoping, in 1919, to persuade Ludwig von Ficker, the editor of the literary journal Der Brenner, to publish his controversial Tractatus Logico-Philosophicus, remarked, "The work is strictly philosophical and at the same time literary" (Monk 1990, 177).

What is it that makes Wittgenstein's philosophical writing also - or perhaps even primarily - literary? "What is it," asks Terry Eagleton in the introduction to his own screenplay about the philosopher, "about this man, whose philosophy can be taxing and technical enough, which so fascinates the artistic imagination?"2 The appeal is especially remarkable, given that Wittgenstein's writing, in the Tractatus, as well as in the Philosophical Investigations and the various posthumously published collections of notes and lectures, is known primarily in English translation - translation that for those of us who are native Austrian speakers often seems to distort what are in the original colloquial speech patterns and conversational rhythms.

\footnotetext{
${ }^{1}$ Cited in Monk 1990, 43.

2 Eagleton, Terry: "Introduction to Wittgenstein" in Eagleton 1993, 5.
} 
This is especially true of Wittgenstein's most obviously "poetic" work, Culture and Value, a collection of aphorisms and meditations on literary, religious, and anthropological topics, assembled from the philosopher's notes by G. H. von Wright in 1977. In the translator's note to the 1998 edition, Peter Winch admits that his original translation (1980) was problematic enough to warrant extensive revision. ${ }^{3}$ But even this new version is characterized by translations like the following:

Die Tragödie besteht darin daß sich der Baum nicht biegt sondern bricht.

You get tragedy where the tree, instead of bending, breaks (CV 3).

More accurately, this would read, "Tragedy occurs when the tree doesn't bend, but breaks." Or again,

Die Religion ist sozusagen der tiefste ruhige Meeresgrund, der ruhig bleibt, wie hoch auch die Wellen oben gehen. (CV 61)

Religion is as it were the calm sea bottom at its deepest, remaining calm, however high the waves rise on the surface.

But "sozusagen" literally means "so to speak," not the coy "as it were," and the "Meeresgrund" would not today be designated as the "sea bottom" but rather as the ocean floor, the stillness at whose deepest point is compared by Wittgenstein to the unshakability of true faith, impervious as that faith is to the passing religious fashions (the waves) of everyday life.

Elizabeth (G. E. M.) Anscombe, the translator of the Investigations and much of the later work, is more faithful to the original but similarly misleading when it comes to Wittgenstein's vernacular phrasing. ${ }^{4}$ The adjective "herrlich," as in "Ist das Wetter heute nicht herrlich?" ("Isn't the weather beautiful today?") for example, is regularly rendered by the rather

${ }^{3}$ Winch, Peter 1998: "Note by Translator". In: CV, xviii-xix. Here and in my citations from the Philosophical Investigations and elsewhere, I have altered the English translation when it has seemed to me incorrect or inappropriate.

${ }^{4}$ Having chosen Anscombe as the official translator of the Philosophical Investigations, Wittgenstein arranged for her to spend some time in Vienna to improve her Oxford-acquired German. Wittgenstein's own last stay in Vienna (December 1949-March 1950), on the occasion of his sister Hermine's death, coincided with Anscombe's, and they evidently met two or three times a week, but he was himself so ill he may not have paid much attention to the actual translation process (see Monk 1990, 562). 
prissy "glorious." "Reigenspiele" is oddly translated as "games like ring-aring-a roses," a name that not only overspecifies, since there are many other circle games (e.g. "A tisket, a tasket"), but also uses a now little-used name for the familiar childrens' game "Ring around the rosie." Or again, the proposition "Es ist uns, als müßten wir die Erscheinungen durchschauen," (PI 90), "We feel as if we had to see through outward appearances" - a common enough state of mind - becomes the more abstract "We feel as if we had to penetrate phenomena."

Even in such ungainly translation, however, Wittgenstein's writing has impressed its readers as decidedly "poetic." But in what sense? In a well-known journal entry of 1934, reproduced in Culture and Value, Wittgenstein remarks:

Ich glaube meine Stellung zur Philosophie dadurch zusammengefaßt zu haben, indem ich sagte: Philosophie dürfte man eigentlich nur dichten.

I think I summed up my position vis-à-vis philosophy when I said: philosophy should really be written only as one would write poetry. (CV 28)

These words, so difficult to render in English, ${ }^{6}$ accord with the frequent links made in Culture and Value between philosophy and aesthetics, for

${ }^{5}$ PI, $§ 21, \S 32$.

${ }^{6}$ Wittgenstein's proposition, as I have noted elsewhere ("'But Isn't the Same at Least the Same?' Wittgenstein and the Question of Poetic Translatability," in Gibson / Huemer 2004, 53n12) is all but untranslatable, because there is no precise English equivalent of the German verb dichten - a verb that means to create poetry but also, in the wider sense, to produce something fictional, as in Goethe's Dichtung und Wahrheit, where fiction is opposed to truth. My own earlier translation: "Philosophy ought really to be written as a form of poetry" (Perloff 1996, xviii and passim) is not quite accurate, since there is no reference to form of writing here. Peter Winch, whose first edition of CV renders Wittgenstein's sentence as "Philosophy ought really to be written only as a poetic composition," revises it for the 1998 edition to read "Really one should write philosophy only as one writes a poem." The word "poem" is misleading - Wittgenstein did not, after all, write poems - and perhaps the most accurate translation is David Schalkwyk's: "Philosophy should be written only as one would write poetry" ("Wittgenstein's 'Imperfect Garden': the Ladders and Labyrinths of Philosophy as Dichtung”, in Gibson / Huemer 2004, 56). Or, to be even more colloquial, one can follow David Antin's “One should really only do philosophy as poetry" (Antin 1998, 161). 
example, "The strange resemblance between a philosophical investigation (perhaps especially in mathematics $<$ ) $>$ and an aesthetic one. (e.g., what's wrong with this dress, what it should look like, etc. ..." (CV 29). But how the two are related, how philosophy is to be written only as poetry: this remains a puzzle, not just for Wittgenstein's reader, but for the philosopher himself. Indeed, no sooner has he made the statement above than Wittgenstein adds somewhat sheepishly, "With these words, I was also acknowledging myself to be someone who cannot quite do what he would like to do" (CV 28). And a few years later: "I squander untold effort to make an arrangement of my thoughts that may have no value whatever" (CV 33).

This is not just false modesty. In its first "poetic" forays, Wittgenstein's writing has a predilection for aphorisms - terse and often gnomic utterances - modeled, it has been suggested, on those of Schopenhauer, ${ }^{7}$ and, more immediately, on the maxims of Heracleitus. In Guy Davenport's words:

"The limits of my language are the limits of my world." "The most beautiful order of the world is still a random gathering of things insignificant in themselves." Which is Heraclitus, which Wittgenstein? "The philosopher," says one of the Zettel,

"is not a citizen of any community of ideas. That is what makes him a philosopher." And: "What about the sentence-Wie ist es mit dem Satz-'One cannot step in the same river twice'?" That Heraclitean perception has always been admired for its hidden second meaning. One cannot step ... it is not only the flux of the river that makes the statement true. But is it true? No, Wittgenstein would smile (or glare), but it is wise and interesting. It can be examined. It is harmonious and poetic."

But unlike Heracleitus, Wittgenstein embedded his philosophical aphorisms into a network of "dry" logical and mathematical propositions of the sort "If $p$ follows from $q$, the sense of " $p$ " is contained in that of " $q$ " (5.123). How to reconcile these two seemingly unlike modes of discourse? This was the problem the young Wittgenstein posed for himself, as we can see in the Notebooks 1914-16, composed during the First World War,

\footnotetext{
7 See, for example, Hans-Johann Glock 2000.

${ }^{8}$ Guy Davenport, "Wittgenstein", in Davenport 2000, 334. The reference is to Wittgenstein's 1933 note: "The man who said that one cannot step into the same river twice said something wrong; one can step into the same river twice," (PO, 167).
} 
sometimes in the midst of battle. On 6.7.16, for example, Wittgenstein confided in his diary, "Colossal strain this last month. Have thought a lot about all sorts of things, but oddly enough, can't make the connection with my mathematical train of thought." The very next day, however, he notes, "But the connection will be made! What cannot be said, can be not said" (GT 69). And a few weeks later, "Yes, my work has expanded from the foundations of logic to the nature of the world." 10

How does such expansion work? In $\S 4.46$ and its sequelae in the Tractatus, Wittgenstein concerns himself with tautology: "the tautology [e.g., either it rains or it does not rain] has no truth-conditions, for it is unconditionally true" (§64.4611). Again (§6.12), "The fact that the propositions of logic are tautologies shows the formal - logical - properties of language, of the world." Now consider the implications of the role of tautology in logic for a discussion of the word happy ( glücklich). In the Notebooks, the word first appears in the entry of 8.7.16 as part of a meditation on belief in God:

I am either happy or unhappy, that's all. It can be said: good or evil do not exist.

He who is happy must have no fear. Not even of death.

Only someone who lives not in time but in the present is happy. (NBK 74)

The first sentence above is a tautology, although of a seemingly different kind from the mathematical and logical tautologies Wittgenstein has been discussing in earlier sections. And now tautology gives way to judgment: to be happy is to have no fear of death, in other words to live in the present, not the future. And so, after insisting that "Death is not an event in life. It is not a fact of the world," Wittgenstein posits:

In order to live happily I must be in agreement with the world.

And that is what "being happy" means ...

The fear of death is the best sign of a false, i.e. a bad, life.

When my conscience upsets my equilibrium, then I am not in agreement with

${ }^{9}$ GT, 68. My translation: there is not yet an English translation of the GT. The methodological importance of this and subsequent passages in the Geheime Tagebücher was first noted by David Antin in "Wittgenstein among the Poets," Modernism/Modernity 154-55.

${ }^{10} \mathrm{NBK}, 79$. 
something. But what is this? Is it the world?

Certainly it is right to say: Conscience is the voice of God.

For example: it makes me unhappy to think that I have offended this or that man. Is that my conscience?

Can one say: "Act according to your conscience whatever it may be"?

(NBK 75)

But the meaning of "conscience" turns out to be as elusive as that of "happiness." Indeed, the final line of this sequence suggests that all one can say is "Lebe glücklich" (Be happy!). And this bit of non-advice leads, in its turn, to the formulation of 29.7.16, that "the world of the happy is different world from the world of the unhappy" - a return to the tautological mode of 8.7.16 that is picked up verbatim in Tractatus 6:43.

The discourse now turns to good and evil and once again the issue of the will, but at the end of this section (NBK 78), we read yet again:

The world of the happy is a different world from that of the unhappy.

The world of the happy is a happy world.

Can there then be a world that is neither happy nor unhappy?

Can one transcend tautology? In his next entry (30.7.16), Wittgenstein writes:

Again and again I come back to this! Simply the happy life is good, the unhappy bad. And if I now ask myself: But why should I be happy, then this of itself seems to me to be a tautological question; the happy life seems to be justified, of itself, it seems that it is the only right life. (NBK 78)

There seems, indeed, to be no further explanation of the happy life - only its assertion:

But one could say: the happy life seems in some sense to be more more harmonious than the unhappy. But in what sense?

What is the objective sign of the happy, harmonious life? Here it is again clear that no such sign, one that can be described, can exist.

This sign cannot be a physical, but only a metaphysical, a transcendental one.

(NBK 78)

There we have it. In circling round and round the word happy, the text cannot reach conclusion. When, some entries later (29.10.16), Wittgenstein declares, "For there is certainly something in the conception that the end of art is the beautiful. And the beautiful is what makes happy" (NBK 86), we have not really gotten anywhere, for beauty, as he well knows, is just as 
elusive as happiness - it is here called "transcendent," which is to say, indefinable. "What cannot be said, can be not said."

The Notebook entries on "happy" were made over a three-month period, and the reader may well wonder why variations on the original distinction between "happy" and "unhappy" are made again and again, both here and in the Tractatus. But repetition with slight permutation - a form of repetition reminiscent of Gertrude Stein or Samuel Beckett rather than of Plato or Heracleitus - is the key to Wittgenstein's method here. ${ }^{11}$ Only by beginning again and again, to use Stein's phrase, by reformulating a particular notion until it gradually manifests or reveals itself, can philosophy make any sort of progress. And "progress" is too strong a word here, for, as Wittgenstein puts it in a 1930 Lecture, "Philosophical analysis does not tell us anything new about thought (and if it did it would not interest us)." Rather, "Philosophy is the attempt to be rid of a particular kind of puzzlement." "In this case, it is only by circling round the proposition "The world of the happy is a happy world," that we begin to understand that happiness, man's most persistent goal, cannot be defined or even specified. Nor is definition or specification necessary. When, for example, we read the famous opening sentence of Tolstoy's Anna Karenina-"Happy families are all alike. Each unhappy family is unhappy in its own way" - we don't stop to ask what Tolstoy means by the words "happy" and unhappy." We know very well what is at stake; we also know that this novel is not going to be about happy families.

But what makes a sentence like "The world of the happy is a happy world" an instance of Dichtung? In a 1931 entry in Culture and Value, we read:

Die Grenze der Sprache zeigt sich in der Unmöglichkeit, die Tatsache zu beschreiben, die einem Satz entspricht (seine Übersetzung ist), ohne eben den Satz zu wiederholen.

${ }^{11}$ In Perloff 2002, 180-90, I discuss Lyn Hejinian's Wittgensteinian long poem "Happily" (Sausalito: Post-Apollo Press, 2000), which plays further variations on the word happy and its cognates and shows how this kind of conceptual poetry works.

${ }^{12}$ Wittgenstein 1980, 35, 1. 
The limit of language manifests itself in the impossibility of describing the reality that corresponds to (is the translation of) a sentence without simply repeating the sentence. (CV 13)

And in Zettel, we read, "Knowledge is actually not translated into words when it is expressed. The words are not a translation of something else that was there before they were."13

Poeticity, these statements suggest, depends upon the conviction that "language is not contiguous to anything else. We cannot speak of the use of language as opposed to anything else." "For if one begins with the actual words spoken or written, word choice and grammar are seen to be everything. The variations on the proposition "The world of the happy is a different world from the world of the unhappy" are essential, not because they say anything "new" - they don't - but because the very act of repetition and qualification, repetition and variation brings home to the reader, as to the philosopher-poet himself, the impossibility of defining happiness, even as its central function in our lives is clearly demonstrated.

Indeed, unlike traditional aphorisms, Wittgenstein's short propositions don't really "say" anything. Or, to put it another way, what they "say" is enigmatic. "Death is not an event in life," (TPG 6.4311), for example, is an arresting aphorism but not because it is true. For death (someone's else) could certainly be an event in my life. And even the specter of my own death determines how I live, what I do. Wittgenstein's sentences are thus characterized, not by their metaphorical force or their use of the rhetorical figures like antithesis and parallelism, but by what I would call their opaque literalism. The sentences say just what they say - no difficult words to look up! - but they remain mysterious, endlessly puzzling, enigmatic. In what context and to whom is it meaningful to say "The world of the happy is a happy world"? Isn't it rather like saying, to quote a famous little poem, "So much depends / upon / a red wheel / barrow / glazed with rain / water / beside the white/ chickens"? And how do we move from one proposition to the next, the decimal system of the Tractatus constituting, as

${ }^{13}$ Wittgenstein 1967, §191. In German, this reads, "Das Wissen wird eben nicht in Worte übersetzt, wenn es sich äußert. Die Worte sind keine Übersetzung eines Andern, welches vor ihnen da war."

${ }^{14}$ Wittgenstein 1980, 112. 
David Antin has so convincingly demonstrated ${ }^{15}$, a framework that defies the very logic it claims to put forward?

\section{No Gaps in Grammar}

In Wittgenstein's later writings, the propositional-aphoristic mode of the Notebooks and the Tractatus gives way to a rather different style. To begin with a representative passage, consider the famous analogy, early in the Investigations, between the language game and the game of chess (PI §30$\S 31)$ :

[End of] §30. One must already know something (or do something with it) in order to be able to ask its name. But what must one know?"

31. When you show someone the king in a game of chess and say, "This is the king, you are not explaining to him how the piece is used --unless he already knows the rules of the game, except for this last identification: the shape of the king. It is possible that he learned the rules of the game without ever having been shown an actual chess piece. The form of the piece here corresponds to the sound or the physical appearance of a word.

But it is also possible that someone has learned the game without ever having learned or formulated the rules. Perhaps first he learned by watching quite simple board games and advanced to increasingly complicated ones. Here again one could give him the explanation "This is the king"-if, for example, one were showing him chess pieces of an unfamiliar design. But again, this explanation teaches him the use of the chess piece only because, as we might say, the place for it had already been prepared. Or even: we might say explanation only teaches him the use of the piece, when its place has been prepared. And in this case, it happens, not because the person to whom we give the explanation already knows the rules, but because, from another perspective, he already has command of the game. ...

Consider this further case: I am explaining chess to someone and begin by pointing to a chess piece and saying "This is the king. It can move like this, etc. etc." In this case, we'll say that the words, "This is the king" (or this one is called "king") only provide a definition if the learner already "knows what a piece in a board game is." That is, if he has already played other games or watched other people playing "with understanding"-and so on. Again, only then would he [be able to ask the relevant question, "What is this called?- that is, this piece in a game.

${ }^{15}$ Antin 1998, 151-56. 
We can say: only someone who already knows how to do something with it can meaningfully ask for its name.

And we can also imagine a situation in which the person questioned answers, "You choose the name", and so the questioner would have to take the responsibility for the whole thing.

In this passage, the terse and enigmatic propositions of the Tractatus are replaced by what looks like a much more casual, free-wheeling discourse. Its central figure is the analogy between a given word and a chess piece: just as the meaning of the various chess figures - king, queen, pawn - depends entirely on their use in the game itself, so, Wittgenstein asserts in $\S 43$, contra the Augustinian theory of language as pointing system where "Every word in the language signifies something" (PI §13), that "the meaning of a word is its use in the language."

Commentary on Wittgenstein's passage often refers to the "chess metaphor" in the Investigations, but it is important to note that here and elsewhere, Wittgenstein's figures are not full-fledged metaphors or even similes. Metaphor is by definition a figure of transference in which $a$ can be substituted for $b$. In Shakespeare's sonnet \#73, for example, we read:

That time of year thou mayst in me behold

Where yellow leaves, or none, or few, do hang

Upon the boughs that shake against the cold,

Bare, ruin'd choirs were late the sweet birds sang.

Here the identity of old age and the autumn of the year is complete; the metaphor, moreover, doubles over in line 4 as the bare branches "where late the sweet birds sang" become the "bare, ruin'd choirs" of medieval churches - perhaps the Gothic vaults of monasteries destroyed during the Reformation. The choristers (sweet birds) no longer sing in the empty church stalls (the tree branches).

Wittgenstein's figures of speech, on the other hand, always begin with the assumption that the analogy between $a$ and $b$ is only that-- an analogy, useful for exemplifying one's points in a philosophical discussion. The chess piece called the king cannot be substituted for a particular word or phrase in a discussion of language: we all know, in other words, that language is not really chess. Or consider the following locutions in Culture and Value: 
A new word is like fresh seed thrown on the ground of the discussion. (CV 4)

Compare the solution of philosophical problems to the gift in the fairytale that magically appears in the enchanted castle and when one looks at it outside in daylight, it is nothing but an ordinary piece of iron (or something similar). (CV 13-14)

Talent is a spring from which fresh water is constantly flowing. But this spring loses its value if it is not used in the right way. (CV 20)

The idea is worn out by now \& no longer usable. ... in the way silver paper, once crumpled, can never quite be smoothed out again. Nearly all my ideas are a bit crumpled. (CV 24)

Language sets everyone the same traps; it is an immense network of well kept wrong turnings. ... So what I should do is erect signposts at all the junctions where there are wrong turnings, to help people past the danger points. (CV 25)

My thinking, like everyone's, has sticking to it the shrivelled husks of my earlier dead thoughts. (CV 27)

Such proverbial statements, as Wittgenstein students have long remarked, are characterized by their homely, everyday wisdom, their common sense. Old ideas can't be recycled any more than silver foil can be smoothed out again; outmoded thoughts are like shrivelled husks; seemingly brilliant solutions to philosophical problems are like those fairy tale gifts that emerge in the harsh light of day as pieces of junk. Wittgenstein knows very well that the items compared are discrete, that words and phrases function only in specific language games.

Now let us return to the chess passage in $\S 31$. Here, as throughout the Investigations, the author presents himself dialogically - as someone having a conversation with someone else. Typically, he begins with a question: here, at the end of $\S 30$, "But what does one have to know?" Question, exclamation, interruption, interpellation: even when, as in the Investigations, there is a written text, not a series of lecture notes recorded by others, Wittgenstein "does" philosophy by setting up everyday dialogues or interviews, as enigmatic as they are childlike. In the chess discussion, for example, Wittgenstein begins by positing that the explanatory sentence "This is the king" makes no sense unless the player already knows the rules of the game. But there are other possibilities. The interlocutor might have learned chess by watching, first simple board games and then more diffi- 
cult ones. "This is the king" might refer to an unusual chess piece, one that doesn't have the usual shape of the king. Or again, the sentence "This is the king" may be spoken by a master of the game to explain what move he is about to make. Or a non-native speaker who knows how to play chess may ask what this particular piece is called in the foreign country he is visiting.

Is it all common sense? Yes and no. Each example appeals to our actual practices, to our reference to how we do things in everyday life. But precisely because we are so familiar with these practices, it is difficult to understand what they mean. It seems as if the exempla in $\S 31$ work up to the authoritative generalization in the penultimate sentence, "We can say: "only someone who already knows how to do something with a given piece can meaningfully ask for its name" - a generalization that actually repeats the final proposition of $\S 30$ cited above, "One must already know something (or do something with it) in order to be able to ask its name." Has the interim passage with its chess examples then made no difference in understanding, especially given that the final sentence--

And we can also imagine a situation in which the person questioned answers, "You choose the name", and so the questioner would have to take the responsibility for the whole thing--

far from providing closure, opens up the debate for further possibilities? Consider what happens in $\S 32$ :

Someone coming into a foreign country will sometimes learn the language of the natives from ostensive definitions that they give him; and he will often have to guess the meaning of these definitions; and will guess sometimes right, sometimes wrong.

And now, I think, we can say: Augustine describes the learning of human language as if the child came into a foreign country and did not understand the language of that country; that is, as if the child already had a language, only not this one. Or again: as if the child could already think, only not yet speak. And "think" would here mean something like "talk to oneself."

The continuity between $\S 31$ and $\S 32$ is at first elusive. Just when we think we understand that the word "king" in chess is meaningless unless we know how to play the game, Wittgenstein shifts ground and attacks the Augustinian theory of language as pointing system from a different angle. The new analogy -wonderfully absurd--is between a stranger in a foreign 
country and a child communicating within its own not-yet-learned language system. Is the child's "thought" then like the foreigner's native language, prior to the "new" language to be learned? The posited analogy is patently absurd, for what could that prior language possibly look and sound like? How does one talk to oneself without talking? As Wittgenstein puts it frequently, does a young child hope before it has learned the word "hope"?

Analogies thus provide sometimes positive, sometimes negative reinforcement: in either case, they lead us to revise our previous understanding of this or that fixed notion. It is this processive, self- corrective, and even self-cancelling nature of Wittgenstein's propositions - their deployment of language as "a labyrinth of paths" (PI §82), their use of countless examples, anecdotes, narratives, and analogies - that gives the text its poetic edge. For the "naturalness" of its talk, its colloquial, everyday language and story-telling is everywhere held in tension with a set of larger assumptions that are as fixed and formally perfect as is the architectural design of the severely modern house Wittgenstein designed for his sister in Vienna. However much the individual exempla in the text are open for discussion and debate, the unstated axiom governing them is that "language is not contiguous to anything else," and that accordingly, the meaning of a word is its use in the language. And the text enacts that theorem, presented as a non-theorem, at every turn. Showing, not telling, is the mode.

Here the testimony of Wittgenstein's Cambridge students is apposite. "His lectures," Norman Malcolm recalls, "were given without preparation and without notes. He told me once he had tried to lecture from notes but was disgusted with the result; the thoughts that came out were 'stale,' or, as he put it to another friend, the words looked like 'corpses' when he began to read them." performance as follows:

At first one didn't see where all the talking was leading. One didn't see, or saw only very vaguely, the point of the numerous examples. And then, sometimes one did, suddenly. All at once, sometimes, the solution to one's problems became clear and everything fell into place. In these exciting moments one realized something of what mathematicians mean when they speak of the beauty of an elegant proof. The solution, once seen, seemed so simple and ob-

${ }^{16}$ Malcolm 1984, 23. 
vious, such an inevitable and simple key to unlock so many doors so long battered against in vain. One wondered how one could fail to see it. But if one tried to explain to someone else who had not seen it one couldn't get it across without going through the whole long story. ${ }^{17}$

In a literary context, the "exciting moments" described here are known as epiphanies. Suddenly, in such Wordsworthian "spots of time," the object of contemplation becomes radiant, and we see into the life of things. Consider Wittgenstein's late notebook entries published under the title On Certainty (Über Gewissheit). ${ }^{18}$ The basic subject of this little book is what one knows and how one knows it: the paragraphs numbered 300-676, written in the last months of Wittgenstein's life try to define the point when doubt becomes senseless - a question that is answerable only by referring it to actual practice. And here Wittgenstein's examples are especially imaginative:

332. Suppose that someone, without wanting to philosophize, were to say, "I don't know if I have ever been on the moon; I don't remember ever having been there. (Why would this person be so alien from us?).

In the first place: how would he know that he was on the moon? How does he picture it to himself? Compare: I don't know if I was ever in the village of X." But I couldn't say this either if X were in Turkey, because I know that I have never been to Turkey.

333. I ask someone, "Have you ever been to China?" He answers, "I don't know." Here one would surely say, "You don't know? Do you have any reason to believe that perhaps you have ever been there? Have you for example ever been near the Chinese border? Or were your parents there at the time you were about to be born? -- Normally, Europeans do know whether they have been to China or not.

334. In other words; the reasonable person doubts such a thing only under such-and-such circumstances. ...

$341 .$. the questions that we raise and our doubts depend on the fact that some propositions are exempt from doubt, like the hinges on which these turn....

${ }^{17}$ Gasking / Jackson 1967, 50. I owe my knowledge of this and related passages to David Antin 1998, 160. Antin's own "talk pieces" are later instances of this Wittgensteinian paradigm.

${ }^{18}$ OC. The selection of notes and their numbering was made posthumously by the editors, not the author. 
343. But it isn't that we just can't investigate everything and are therefore forced to be satisfied with assumptions. If I want the door to move, the hinges must be intact.

344. My life consists in that there are certain things I am content to accept.

Here is the negative capability of the late Wittgenstein - the capacity, in Keats's words, "of being in uncertainties, Mysteries, doubts without any irritable reaching after fact \& reason" $" 19$ - a mental state closely allied to the moment of poetry. Of course, Wittgenstein suggests, one can always demand specification of a proposition to the point where there could be certainty, as in " 2 × $2=4$," but, even in this case, "the spoken or written sentence ' $2 \times 2=4$ ' might in Chinese have a different meaning or be pure nonsense" (OC 10). Not what a statement is but what one does with it is what matters. So, to use the hinge analogy above, if you want the door to move, the hinges must work. In everyday life we know quite well whether or not we have been to China or on the moon, just as we know that we have two hands and two feet without looking at them to check out the truth. "Ordinary language is alright.",20

But Wittgenstein's "ordinary language" is of course extraordinary. In the passage above (\$332-43) and throughout On Certainty, persuasion depends on the poet-philosopher's astonishing rhetorical skill. Examples must be short and concrete; they must speak to the interlocutor's everyday experience, using conversational speech patterns, reinforced by vivid analogies like that of words turned to corpses or worn-out ideas like crumpled silver foil. The exempla must meet the test of common sense; indeed, they must be so literal that they make us laugh. Even in our own age of moon exploration, the response "I don't know" to the question, "Have you ever been on the moon?" is absurd. Indeed, the absurdity of many of Wittgenstein's propositions shows their affinity to the joke, the riddle, or the tall tale, as these variants appear in the language-game itself: "Imagine a language-game "When I call you, come in through the door. In an ordinary case, it will be impossible to doubt that there really is a door" (OC §391). A child, presented with such a possibility, would either laugh or put for-

\footnotetext{
19 John Keats, Letter to George and Tom Keats, 21, 27 December 1817, in Keats 1982, 43.

${ }^{20}$ Wittgenstein 1965, 28.
} 
ward an alternate game - for example, "Let's pretend none of the things in this room exist." And therein would lie a different language game, a different poetic act.

\section{The Right Tempo}

In the much-cited Preface to the Philosophical Investigations, Wittgenstein describes the method whereby he ordered the "remarks, short paragraphs, of which there is sometimes a fairly long chain about the same subject" into the larger structure of the book:

After several unsuccessful attempts to weld my results together into such a whole, I realized I should never succeed. The best that I could write would never be more than philosophical remarks; my thoughts were soon crippled if I tried to force them on in any single direction against their natural inclination. And this was of course connected with the very nature of the investigation. Namely, it forces us to travel over a wide range of thoughts, criss-cross [ $\mathrm{kreuz}$ und quer], in all directions. ...r Thus this book is really only an album. (PI unpaginated).

An album is most typically a medley, a commonplace book or loose collection of disparate items, collaged together kreuz und quer, without much thought of the controlling structure. But despite this disclaimer, Wittgenstein's "remarks" are the result of much more intensive dichten than is usually thought. Etymologically, the verb dichten comes from the adjective dicht (thick, dense, packed): dichten originally meant "to make airtight, watertight; to seal the cracks (in a window, roof, etc.)" - in other words, something like the Zen phrase "to thicken the plot."

Poets, indeed fiction-makers of all stripes, are those that make thick or dense, that pack it in. Again and again, in Culture and Value and related texts, Wittgenstein talks of the need for slow reading:

Sometimes a sentence can be understood only if it is read at the right tempo. My sentences are all to be read slowly. (CV 65)

Thoughts rise to the surface slowly, like bubbles. (CV 72)

Of the sentences that I write down here, only the occasional one represents a step forward; the others are like the snip of the barber's scissors, which must be kept in motion so as to make a cut with them at the right moment. (CV 76) 
Raisins may be the best part of a cake; but a bag of raisins is no better than a cake; and he who is in a position to give us a bag full of raisins, cannot necessarily bake a cake with them, let alone do something better.

I am thinking of [Karl] Kraus \& his aphorisms, but of myself too \& my philosophical remarks.

A cake is not, as it were, thinned out raisins (CV 76)

The last remark here is especially telling. Aphorisms, so central to the Tractatus and earlier work, cannot in themselves make a poeticphilosophical discourse. If they remain discrete, like so many separate raisins in a bag, they fail to cohere into a fully-formed "cake." But coherence, in this instance, is not a matter of linearity, of logical or temporal movement from a to $\mathrm{b}$ to $\mathrm{c}$. For Wittgenstein, the criss-crossing of threads must be dicht - thick and dense - and, as in the case of lyric poetry, only slow reading, can unpack the meanings in question.

"My sentences must be read slowly." The necessity, in an information age, of slowing down the reading process, was central to the thinking of many of Wittgenstein's contemporaries - for example, the Russian avant-gardists Velimir Khlebnikov and Alexeii Kruchenykh: the term ostranenie (estrangement, defamiliarization) was always associated with slowing down the reading (or viewing) process in art. Duchamp's concept of the delay, as in calling his Large Glass (The Bride Stripped Bare by her Bachelors, Even) a "delay in glass," is another instance. To say "Philosophy must be written only as one would write poetry" is to be aware of the need for density and resonance - rather than logic and sequential argument-- in the verbal construct.

One of Wittgenstein's most intriguing works in this regard is the "Remarks on Frazer's Golden Bough (1936), first edited and published in 1967 by Rush Rhees. ${ }^{21}$ On the surface, this seems to be a rather loosely organized set of scattered "remarks": it begins "One must start out with error and convert it into truth," and then contains the isolated lyric line, "I must plunge into the water of doubt again and again" (PO 119). Again and again

21 "Remarks on Frazer's Golden Bough," in PO, 115-55. In their head note, the editors point out that the first bilingual book edition of this text (Retford: Brynmilll 1979) left out a considerable number of the remarks; "the extant editions disagree about what to include and what to leave out of Wittgenstein's remarks" (116). There is, then, no definitive text of this essay. 
is the key here: in what follows, Wittgenstein repeats, questions, challenges, exclaims, circling round and round the issue of Frazer's misunderstanding of "primitive" religious practices in The Golden Bough. "One would like to say: This and that incident have taken place; laugh if you can" (PO 123). Or, "What a narrow spiritual life on Frazer's part! As a result: how impossible it was for him to conceive of a life different from that of the England of his time!" (PO 125). And even more scathingly, "Why shouldn't it be possible for a person to regard his name as sacred? It is certainly, on the one hand, the most important instrument which is given to him, and, on the other, like a piece of jewelry hung around his neck at birth" (PO 126-27).

Only after pages of such "criss-cross" emotional commentary, does Wittgenstein zero in on what is his central case: that if the vegetation ceremonies of the peoples in question are understood, not as opinions or beliefs, but as practices, their behavior will emerge as not so "primitive" after all:

I read among many similar examples, of a Rain-King in Africa to whom the people pray for rain when the rainy period comes. But surely that means that they do not really believe that he can make it rain, otherwise they would do it in the dry periods of the year in which the land is "a parched and arid desert." For if one assumes that the people formerly instituted this office of Rain-King out of stupidity, it is nevertheless certainly clear that they had previously experienced that the rains begin in March, and then they would have had the Rain-King function for the other part of the year. Or again, toward morning, when the sun is about to rise, rites of daybreak are celebrated, but not during the night, when they simply burn lamps. (PO 137).

And the essay now multiplies examples of similar misunderstandings on Frazer's part, culminating in the assertion, "If they [the primitive people Frazer talks of] were to write it down, their knowledge of nature would not differ fundamentally from ours. Only their magic is different" (PO 141).

Remarks on Frazer's Golden Bough was, of course, not intended for publication, at least not in the present form, and so our expectations of it are different from those we have of the Investigations. But when we remember that even the latter, his most "finished" work, was undergoing continual change between the time of its "completion" and Wittgenstein's 
death in $1951,{ }^{22}$ we can see that the formal constraints are quite similar. To insure that the reader will absorb them "slowly," Wittgenstein's sentences are paratactic and metonymic; they circle around a "point," at first quietly, even casually, then with increasing deliberation, until the "meaning" of this or that argument suddenly crystallizes. From the gnomic aphorisms of the Tractatus to the "common-sense" analogies that multiply and spill over into the next paragraph in the Investigations and On Certainty, Wittgenstein's writings enact their central motive: words and phrases can be understood only in their particular context, their use. Not what one says but how one says it is the key to doing philosophy. And that, of course, is what makes it poetry as well.

\section{Literature}

Antin, David 1998: "Wittgenstein among the Poets". Modernism/Modernity 5(1), 14966 .

Davenport, Guy 1981: The Geography of the Imagination. San Francisco: North Point Press.

Dauber, Kenneth / Walter Jost (eds.) 2003: Ordinary Language Criticism: Literary Thinking after Cavell after Wittgenstein. Evanston: Northwestern Univ. Press.

Eagleton, Terry 1993: Wittgenstein: The Terry Eagleton Script; The Derek Jarman Film. London: Film Institute.

Gasking D. A. T. / Jackson, A. C. 1967: "Wittgenstein as a Teacher". In: Fann, K. T. (ed.): Ludwig Wittgenstein: The Man and his Philosophy. New Jersey: Humanities Press.

Gibson, John / Huemer, Wolfgang (eds.) 2004: The Literary Wittgenstein. New York: Routledge.

Glock, Hans-Johann 2000: "Schopenhauer and Wittgenstein". In: Janaway, Christopher (ed.): The Cambridge Companion to Schopenhauer. Cambridge: Cambridge University Press, 422-58.

Keats, John 1982: Letters of John Keats, ed. Robert Gittings. Oxford: Oxford University Press.

${ }^{22}$ See especially Wittgenstein 1982. In these volumes, Part II of the Investigations is heavily revised and expanded. 
Malcolm, Norman 1984: Ludwig Wittgenstein: A Memoir, 2d. edition with Wittgenstein's Letters to Malcolm. Oxford: Oxford University Press.

Monk, Ray 1990: Ludwig Wittgenstein: The Duty of Genius. New York: Macmillan.

Perloff, Marjorie 1996: Wittgenstein's Ladder: Poetic Language and the Strangeness of the Ordinary. Chicago: University of Chicago Press.

Perloff, Marjorie 2002: $21^{\text {st }}$-Century Modernism. Oxford: Blackwell.

Wittgenstein, Ludwig 1965: The Blue and Brown Books. Preliminary Studies for the "Philosophical Investigations". $2^{\text {nd }}$ Edition. New York: Harper \& Row.

Wittgenstein, Ludwig 1967: Zettel, bilingual edition, ed. G. E. M. Anscombe and G. H. von Wright; trans. G. E. M. Anscombe. Berkeley: University of California Press.

Wittgenstein, Ludwig 1969: On Certainty, ed. G. E. M. Anscombe \& G. H. von Wright. New York: Harper \& Row. (OC)

Wittgenstein, Ludwig 1979 Notebooks 1914-1916. $2^{\text {nd }}$ Edition, ed. G. H. von Wright and G. E. M. Anscombe, trans. G. E. M. Abscombe. Chicago: University of Chicago Press. (NBK)

Wittgenstein, Ludwig 1980: Wittgenstein's Lectures Cambridge, 1930-32. From the Notes of John King and Desmond Lee. Ed. Desmond Lee. Chicago: University of Chicago Press.

Wittgenstein, Ludwig 1982/1992: Last Writings on the Philosophy of Psychology, 2 vols. Ed. G. H. von Wright and Heikki Nyman.

Wittgenstein, Ludwig 1991: Geheime Tagebücher 1914-1916, ed. Wilhelm Baum. Vienna: Turia and Kant. (GT)

Wittgenstein, Ludwig 1993: Philosophical Occasions 1912-1951, ed. James C. Klagge and Alfred Nordmann. Indianapolis / Cambridge: Hackett. (PO)

Wittgenstein, Ludwig 1997: Philosophische Untersuchungen / Philosophical Investigations. $2^{\text {nd }}$ Edition, trans. G. E. M. Anscombe. Oxford: Blackwell. (PI)

Wittgenstein, Ludwig 1998: Vermischte Bemerkungen: Eine Auswahl aus dem Nachlaß / Culture and Value: A Selection from the Posthumous Remains, Rev. ed, edited by G.H. Von Wright, Oxford: Blackwell. (CV) 